\title{
During one-lung ventilation, K.I.S.S.—Keep It Simple Surgeons
}

\author{
Benny Weksler, MBA, MD
}

\author{
From the Division of Thoracic Surgery, University of Tennessee Health Science Center, Memphis, Tenn. \\ Disclosures: B.W. is a proctor for Intuitive Surgery, a consultant for Bard, and is on the Scientific Advisory Board \\ of Biodesix. \\ Received for publication March 3, 2017; accepted for publication March 10, 2017; available ahead of print April \\ $12,2017$. \\ Address for reprints: Benny Weksler, MBA, MD, Division of Thoracic Surgery, University of Tennessee Health \\ Science Center, 1325 Eastmoreland Ave, Suite 460, Memphis, TN 38104 (E-mail: bweksler@uthsc.edu). \\ J Thorac Cardiovasc Surg 2017;154:367-8 \\ $0022-5223 / \$ 36.00$ \\ Copyright (c) 2017 by The American Association for Thoracic Surgery \\ http://dx.doi.org/10.1016/j.jtcvs.2017.03.025
}

Hypoxemia during 1-lung ventilation is potentially dangerous and presents a significant challenge to surgeons and anesthesiologists, particularly during minimally invasive surgery. The incidence of hypoxemia was 3\% in a large series of 1170 patients, but it can be as high as $24 \%$ in the hands of less-experienced anesthesiologists. ${ }^{1,2}$ Continuous positive airway pressure to the nonventilated lung is highly effective in preventing and treating hypoxemia during 1-lung ventilation, but continuous positive airway pressure often will inflate the lung and during minimally invasive thoracic procedures (video-assisted or robotic) may prevent the completion of the procedure. ${ }^{3}$ In 2000, Baraka and colleagues ${ }^{4}$ created a contraption to insufflate oxygen through a T-piece to the nonventilated lung to prevent hypoxemia. Over the years, many thoracic surgeons have used oxygen insufflation to the nonventilated lung in the hopes of preventing or treating hypoxemia, without any evidence that the technique is useful. Although hypoxemia during thoracic surgery continues to be a problem, few prospective trials have addressed the issue.

In the current issue of the Journal, Jung and colleagues ${ }^{5}$ describe their careful and well-thought out randomized trial of apneic lung insufflation during 1-lung ventilation. ${ }^{5}$ The authors initiated oxygen insufflation after 15 minutes of 1-lung ventilation to prevent delays in lung collapse and prevent hypoxemic vasoconstriction and insufflated $3 \mathrm{~L} / \mathrm{min}$ of oxygen using a suction catheter positioned 1 to $2 \mathrm{~cm}$ beyond the end of the endotracheal tube in the nonventilated lung. The authors kept both the anesthesia team and the surgeons performing procedures that required 1lung ventilation blind to the intervention by placing the catheter in all patients and covering the oxygen flow meter. Among the patients who received apneic oxygen insufflation, there were no instances of peripheral oxygen saturation less than $90 \%$ compared with peripheral oxygen saturation less than $90 \%$ in $18 \%$ of the patients who did not receive supplemental oxygen. The authors did not

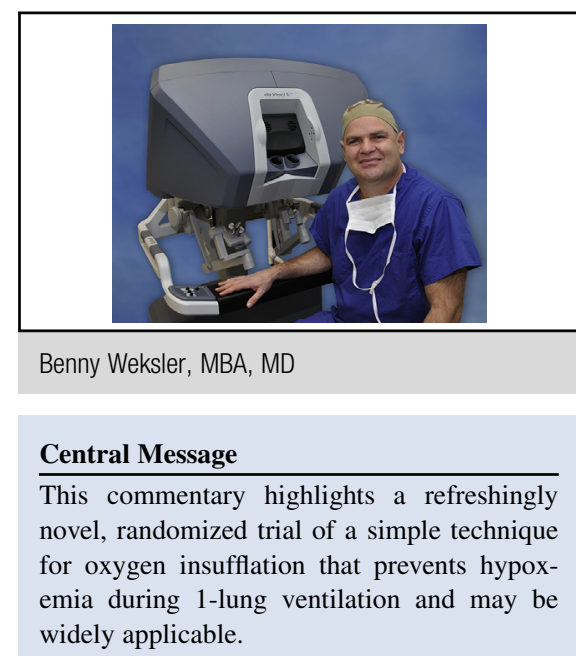

See Article page 360.

notice any lung inflation in the patients receiving supplemental oxygen. There were no differences in other intraoperative or postoperative variables that they examined.

Jung and colleagues ${ }^{5}$ have demonstrated that a simple method will prevent hypoxemia during 1-lung ventilation. This is an elegant trial that provides scientific data addressing a vexing problem that all thoracic surgeons eventually face. Because so much of what we do is not based on sound scientific data, it is refreshing to see a randomized trial addressing an everyday surgical problem. The method is so simple and low risk that it might be applicable in all patients, which de facto changes the current standard of care. One important point requiring further investigation is the use of the procedure in patients with significant decreases in lung function who are borderline candidates for surgery. The study population had relatively preserved lung function, and most patients had a forced expiratory volume in 1 second greater than 2 liters and preserved diffusion capacity of the lung for carbon monoxide. The authors purposely excluded patients with compromised lung function, which is appropriate for the trial, but leaves the reader wondering if the method could be effective in patients at higher risk for hypoxemia during 1-lung ventilation.

\section{References}

1. Brodsky JB, Lemmens HJ. Left double-lumen tubes: clinical experience with 1,170 patients. J Cardiothorac Vasc Anesth. 2003;17:289-98.

2. Ehrenfeld JM, Mulvoy W, Sandberg WS. Performance comparison of right- and left-sided double-lumen tubes among infrequent users. J Cardiothorac Vasc Anesth. 2010;24:598-601. 
3. Karzai W, Schwarzkopf K. Hypoxemia during one-lung ventilation: prediction, prevention, and treatment. Anesthesiology. 2009;110:1402-11.

4. Baraka A, Lteif A, Nawfal M, Taha S, Maroun M, Khoury S, et al. Ambient pressure oxygenation via the nonventilated lung during video-assisted thoracoscopy. Anaesthesia. 2000;55:602-3.
5. Jung DM, Ahn HJ, Jung SH, Yang M, Kim JA, Shin SM, et al. Apneic oxygen insufflation decreases the incidence of hypoxemi during one-lung ventilation in open and thoracoscopic pulmonary lobectomy: a randomised controlled trial. $J$ Thorac Cardiovasc Surg. 2017;154:360-6. 